\title{
The relationship between blood pressure and cognitive function
}

\author{
Vera Novak and Ihab Hajjar \\ Division of Gerontology, Beth Israel Deaconess Medical Center and Harvard Medical School, 110 \\ Francis Street, LMOB Suite 1b, Boston, MA 02215, USA (V. Novak, I. Hajjar)
}

\begin{abstract}
The relationship between blood pressure (BP) and cognitive outcomes in elderly adults has implications for global health care. Both hypertension and hypotension affect brain perfusion and worsen cognitive outcomes. The presence of hypertension and other vascular risk factors has been associated with decreased performance in executive function and attention tests. Cerebrovascular reserve has emerged as a potential biomarker for monitoring pressure-perfusion-cognition relationships. A decline in vascular reserve capacity can lead to impaired neurovascular coupling and decreased cognitive ability. Endothelial dysfunction, microvascular disease, and mascrovascular disease in midlife could also have an important role in the manifestations and severity of multiple medical conditions underlying cognitive decline late in life. However, questions remain about the role of antihypertensive therapies for long-term prevention of cognitive decline. In this Review, we address the underlying pathophysiology and the existing evidence supporting the role of vascular factors in late-life cognitive decline.
\end{abstract}

\section{Introduction}

The relationship between blood pressure (BP) and cognitive outcomes in the elderly has gained attention because of its implications for global health care. Hypertension affects more than a third of the population worldwide, ${ }^{1}$ especially those older than 65 years, of whom 65 $75 \%$ report having hypertension. ${ }^{2}$ The prevalence of asymptomatic hypotension in this age group is $16.2 \% .^{3}$ Both high and low BP have been linked with cognitive decline and dementia. The pathophysiology of the relationship between BP and cognition is unclear, but hypo perfusion and neurodegeneration have emerged as possible underlying mechanisms. ${ }^{4-7}$ The BP levels that should be targeted to achieve optimal perfusion while preventing cognitive decline are still being debated.

In this review, we summarize the evidence indicating that decline in vascular reserve capacity, which is associated with impaired neurovascular coupling, is one of the main pathways linking BP to cognitive decline. We also discuss physiological monitoring and MRI studies that improve our understanding of the pathophysiology linking abnormalities in brain vascular reserve and cognitive decline, and present supporting clinical evidence for the $\mathrm{BP}-$ cognition relationship from epidemiological studies and clinical trials of antihypertensive therapies.

\footnotetext{
(C) 2010 Macmillan Publishers Limited. All rights reserved

Correspondence to: V. Novakvnovak@bidmc.harvard.edu.

Competing interests: The authors, the journal Chief Editor B. Mearns and the CME questions author C. P. Vega declare no competing interests.

Author contributions: V. Novak and I. Hajjar contributed to discussion of content for the article, researched data to include in the manuscript, reviewed and edited the manuscript before submission, and revised the manuscript in response to the peer-reviewers' comments.
} 


\section{BP and cognition}

Both hypertension and hypotension are associated with disruptions in neurovascular coupling, which lead to a decrease in vascular reserve capacity and can cause microvascular disease, stroke, cognitive decline, and dementia. Factors other than perfusion, such as genetic predisposition, autonomic failure, and neurodegeneration associated with diabetes mellitus, Alzheimer disease, Parkinson disease, and Lewy body disease, have also been proposed to contribute to the progression of dementia, although the mechanisms underlying these associations are still unclear.

\section{BP and brain perfusion}

Neurovascular coupling is a concept that refers to the interactions between neurons, vessels and other cells of the nervous system (such as astrocytes and other glial cells), considered as the basis of the relationship between neuronal activity, hemodynamic factors, and cell-tocell signaling. ${ }^{8}$ These interactions synchronize increases in neuronal activity with perfusion and thus facilitate communication within the functional networks of the brain.

Neurovascular coupling enables redistribution of cerebral blood flow (CBF) to areas of increased activity and metabolic demand, as well as allowing adjustments in response to beat-to-beat changes in transmural pressure and central autonomic nervous system activity. The three main components of neurovascular regulation are neurogenic, metabolic (mediated by molecules such as $\mathrm{O}_{2}, \mathrm{CO}_{2}$, ATP, and glucose, among others), and myogenic regulation. Neurogenic regulation refers to tonic and phasic activity within the network of the central autonomic nervous system, which includes noradrenergic, serotoninergic, cholinergic, and dopaminergic neuronal activity, and also modulates endothelial function and signaling among neuronal networks. These regulatory systems, which converge in associative cortical areas, are widely involved in numerous cognitive and motor functions.

Changes in BP are associated with changes in brain perfusion and metabolism. The capacity of the neurovascular units within vascular territories and of the whole brain to respond to variation in BP and increased metabolic demands is referred to as the brain vascular reserve. Endothelial dysfunction associated with advanced age and risk factors such as hypertension and diabetes set the stage for altered neurovascular coupling and regional decline in vasomotor reserve capacity. ${ }^{9}$ In this setting, increased oxidative stress and inflammation lower the intrinsic threshold for cell survival. ${ }^{10}$

\section{Integration of multiple pathways}

The combination of advanced age with hypertension and other risk factors provides a background for multifaceted interactions in pathophysiological pathways that lead to cognitive decline and dementia. Examples of these pathways are those involved in small vessel disease, altered regulation of blood flow, presence of white matter hyperintensities (WMHs), deposition of amyloid $\beta$ A4 protein and neurofibrillary tangles, altered cholinergic transmission, and autonomic failure, as well as those resulting from genetic predisposition (such the $A P O E \varepsilon 4$ genotype). These pathways interact in a complex pattern. For example, clearance of amyloid $\beta$ A4 protein from the brain is dependent on vascular reactivity, which in turn is affected by small vessel disease, whereas the presence of comorbidities associated with small vessel disease may contribute to the pathology of Alzheimer disease. Interactions between multiple pathophysiological pathways result in neuronal death, cortical and subcortical white matter disconnection, and functional decline, ${ }^{11}$ primarily in the associative areas of frontal and temporal cortices, which are involved in complex functions such as decision-making and memory. 
BP has been increasingly linked not only with the pathophysiology of Alzheimer dementia and vascular dementia (the second most common form of dementia, in which several vascular mechanisms, such as those associated with stroke, lacunar infarcts, small vessel disease, or chronic cardiovascular disease, are linked with severe cognitive impairment), but also with mild cognitive impairment (MCI) and mild cognitive disorders (MCDs). MCI is as a state of cognitive deterioration in which the affected person does not have either normal cognitive function or dementia; objective or subjective evidence of cognitive deterioration is present, but activities of daily living are preserved and complex functions are intact or minimally impaired. Subcategories of this classification are single or multidomain MCI with or without memory involvement (amnestic or nonamnestic MCI, respectively). ${ }^{12} \mathrm{MCDs}$ are a broader spectrum of preclinical cognitive (including neurodegenerative) pathologies. ${ }^{13}$ The relationship between BP and these pathologies emphasizes the importance of altered neurovascular coupling in all of these settings. ${ }^{14}$ Nevertheless, the relationship between BP and cognition throughout life is still not well understood, with some studies showing a strong association between cognitive decline and hypertension, others showing an association with declining BP, and others showing no such associations. The actual relationship between BP and cognition might be predictable over the course of a lifespan if neurovascular coupling is considered as a hidden variable and the duration of exposure of neurons and cerebral perfusion to fluctuations in BP is assessed. Mounting evidence suggests that the associations between endothelial dysfunction, microvascular disease, and macrovascular disease could have an important role in the manifestations and severity of multiple medical conditions that underlie cognitive decline late in life.

\section{Assessment of vascular reserve}

Two biomarkers of vascular reserve are clinically relevant-pressure autoregulation and $\mathrm{CO}_{2}$ vasoreactivity. ${ }^{15}$ Conditions affecting $\mathrm{BP}$ regulation are associated with alterations in these markers, which can be assessed with several MRI techniques (Table 1).

\section{Autoregulation}

BP autoregulation maintains a fairly stable perfusion over the range of mean systemic pressures $60-150 \mathrm{mmHg}$. Static autoregulation refers to long-term 'steady-state' control, whereas dynamic autoregulation refers to the adaptation of perfusion to beat-to-beat variations in intracranial pressure and BP. ${ }^{16}$ Numerous conditions, such as hypertension, ${ }^{17}$ hypotension, ${ }^{18}$ diabetes, ${ }^{19}$ vascular disease, and stroke, ${ }^{20-22}$ as well as smoking, impair autoregulation. With impaired autoregulation, the sigmoid autoregulation curve that expresses the relationship between $\mathrm{CBF}$ and mean BP becomes more linear and perfusion becomes pressure-dependent (Figure 1). Hypertension and hypotension alter CBF regulation, and the lower limits of the autoregulation window are shifted toward higher BP values. Therefore, the autoregulation range is narrowed and the slope of the CBF-BP curve becomes steeper. In this setting, vasodilatation in response to low BP can be reduced and vasoconstriction in response to high BP can be increased.

Orthostatic and postprandial hypotension are defined as a $\geq 20 \mathrm{mmHg}$ decline in systolic BP when in an upright position, or within $1 \mathrm{~h}$ after a meal, respectively. ${ }^{23}$ In hypotension syndromes, altered BP regulation leads to supine hypertension. In individuals with hypotension syndromes, the mean BP can thus vary with postural change, from $80 \mathrm{mmHg}$ in the upright position to $>180 \mathrm{mmHg}$ in the supine position. Accordingly, in these individuals the autoregulated range can be narrowed to $\approx 20 \mathrm{mmHg}^{24}$ when in the upright position, or expanded over a wide range of pressures (mean BP 110-180 mmHg), and the lower autoregulation threshold can be shifted toward high BP values. ${ }^{18}$ Therefore, in the setting of hypotension syndromes, the upright-position BP might be below the range of effective 
regulation, leading to perfusion decline. In these patients, daily living activities can induce hypoperfusion ${ }^{25}$ and lead to syncope, ${ }^{26}$ falls, or ischemia and cognitive changes. ${ }^{27}$

Transcranial Doppler ultrasonography (TCD) enables noninvasive assessment of dynamic autoregulation from spontaneous fluctuations in BP and CBF velocity 28 at baseline and during postural interventions, such as standing up or head-up tilt. ${ }^{15,29} \mathrm{CBF}$ fluctuations at $0.01-0.03 \mathrm{~Hz}$ have been linked with intracranial pressure, ${ }^{30}$ central sympathetic activity, ${ }^{31}$ microcirculation, and cerebral oxygenation. ${ }^{32}$

Autoregulation is quantified using mathematical modeling, Fourier transform analysis, coherence function, and more-recently developed nonlinear methods. ${ }^{19,33-35}$ A substantial phase lead of CBF velocities with respect to the peripheral BP indicates intact autoregulation. ${ }^{28,36,37}$ Nonlinear approaches, such as multiple coherence ${ }^{15}$ and multimodal pressure-flow (MMPF), enable assessment of autoregulation at multiple timescales and have greater sensitivity and specificity for detection of autoregulation defects than linear methods. ${ }^{19,35}$ The MMPF method demonstrates, for example, that hypertension and diabetes substantially impair autoregulation to an observable degree after ischemic stroke (Figure 2). ${ }^{35}$

\section{$\mathrm{Co}_{2}$ vasoreactivity}

$\mathrm{CO}_{2}$ vasoreactivity is measured from $\mathrm{CBF}$ responses to vasoconstrictor (such as hypocapnia or hyperventilation) and vasodilatating (such as $\mathrm{CO}_{2}$ rebreathing, breath holding, or acetazolamide administration) stimuli. ${ }^{38}$ Vasoreactivity is calculated as the percent flow change per $\mathrm{CO}_{2}$ change. TCD-based assessment of vasoreactivity is restricted to $\mathrm{CBF}$ velocity measurements in one or two vascular territories. Advances in imaging techniques based on three-dimensional continuous arterial spin labeling (3D CASL) MRI, bloodoxygen-level-dependent (BOLD) MRI, and single photon emission computed tomography (SPECT) imaging, however, enable the assessment of vasoreactivity in anatomical regions and vascular territories (Table 1). ${ }^{39}$ These techniques have advantages over TCD by providing a better assessment of the regional distribution of vasoreactivity, but lack temporal resolution and values need to be averaged over a period of time (a few minutes). Aging, hypertension, diabetes, or stroke reduce vasodilatation ${ }^{40,41}$ in multiple vascular territories, whereas vasoconstriction can be preserved. ${ }^{42}$ The variability of CBF responses to pathogenic stimuli underscores the importance of underlying small and large vessel disease that can lead to chronic hypoperfusion in numerous brain regions.

\section{Assessment of microvascular disease}

Cerebromicrovascular disease associated with hypertension and other cardiovascular risk factors, including age, is linked with regional hypoperfusion and brain volume loss (Figure 3 ), as well as with neuronal degeneration and cognitive decline in elderly people. ${ }^{43-48}$ Cerebromicrovascular disease accelerates CBF decline with age $e^{49-52}$ and is associated with regional differences in vasoregulation and reserve capacity. ${ }^{9}$

MRI has enabled the visualization of microvascular disease (that is, lacunar infarctions, microinfarctions, microbleeds, iron deposits, and diffused WMHs) with unprecedented resolution (Figure 4). Of note, microinfarcts and iron deposits in patients with hypertension can be visible at ultrahigh-field MRI at $8 \mathrm{~T}$, but not at lower resolutions (Figure 4). ${ }^{53} \mathrm{WMHs}$ are associated with global and regional brain atrophy, including hippocampal atrophy; ${ }^{51}$ reduced functional neuronal mass, which indicates that an active neurodegenerative process has taken place, ${ }^{54}$ lower perfusion ${ }^{55}$ and metabolism ${ }^{56}$ in the white matter, which affect preferentially frontal, parietal, and temporal cortices; lower oxygenation in the frontal lobes $;{ }^{57}$ slower CBF velocities; ${ }^{58}$ cognitive decline and executive dysfunction $;{ }^{59}$ vascular 
dementia $;{ }^{60-62}$ motor impairment; ${ }^{63}$ and depression. ${ }^{64}$ The presence of WMHs was also associated with a 24-year increase in diastolic $\mathrm{BP}(>10 \mathrm{mmHg}$; odds ratio [OR] $2.6,95 \% \mathrm{CI}$ 1.3-5.1), systolic BP (>40 mmHg; OR 2.0, 95\% CI 1.2-3.4), pulse pressure (>24 mmHg; OR $1.8,95 \%$ CI 1.1-2.7), and mean arterial pressure (>6 mmHg; OR 2.2, 95\% CI 1.43.4). ${ }^{65}$

\section{$\mathrm{BP}$, cognitive decline, and dementia}

Epidemiological studies (Tables 2-5) support the evidence for an age-dependent association between BP and decline in cognitive function and/or dementia. Specifically, high BP (especially high systolic BP) in middle age is consistently associated with late-life cognitive impairment and dementia. ${ }^{58}$ Therefore, treatment of high sytolic BP during midlife might be an effective strategy to reduce the risk of late-life dementia and cognitive impairment. ${ }^{66} \mathrm{By}$ contrast, the association between low BP and cognitive dysfunction is more complicated, and is, therefore, less well understood. Orthostatic hypotension in middle age can indicate autonomic failure (a failure in BP regulation causing fluctuations in BP and perfusion during daily living activities), but is a sign of frailty (onset of rapid decline) in old age.

\section{Hypertension and risk of cognitive decline}

Hypertension in middle age and cognition-A combination of hypertension and other vascular risk factors in the middle-aged population could accelerate worsening of cognitive performance late in life (Table 2). Data from a prospective study of a population 40-69 years old with a 12-year follow-up showed that individuals with either central obesity (the uppermost quartile) or hypertension had poorer performance on executive functioning and visual-motor skills tests (Trail Making Test Part B, and Visual Reproduction Immediate and Delayed Recall tests) than other individuals in the population. ${ }^{67}$ This association was not observed, however, in leaner individuals with hypertension, and neither hypertension nor obesity was individually or synergistically related to verbal memory (immediate or delayed recall). In another study, obesity was related to increased cerebroascular resistance, slowed CBF velocities, increased systolic BP, and male sex. ${ }^{68}$ Hypertension and diabetes were associated with a decline in the ability to perform executive function tasks (Delayed Word Recall Test, Digit Symbol Substitution Test, and Word Fluency Test) in the ARIC study. ${ }^{69}$ In the NHANES III study, ${ }^{62}$ stroke and the APOE 84 genotype were independent predictors of verbal memory decline assessed by the Delayed Word Recall Test. Metabolic syndrome, hypertension, and stroke were independently associated with cognitive decline as assessed by the Word Fluency Test. Furthermore, the combination of hypertension and diabetes was associated with decreased cognitive ability as assessed by three measures of cognitive function (Simple Reaction Time Test, Symbol Digit Substitution Test, and Serial Digit Learning Test). ${ }^{70}$ These findings indicate that a complex composed of several aspects of vascular disease (such as stroke, lacunar infarcts, and WMHs) is linked to deficits in attention and executive function, rather than to a decline in memory (a feature clinically linked with Alzheimer disease). In the REGARDS cross-sectional study, ${ }^{71}$ the odds of experiencing a stroke symptom increased by $35 \%$ with each of the following factors: hypertension, diabetes, smoking, lack of exercise, and depressive symptoms; the odds of cognitive impairment increased by $12 \%$ with each modifiable factor, in an additive manner. ${ }^{71}$ A subsequent analysis of the REGARDS study showed that an increment of 10 $\mathrm{mmHg}$ in diastolic BP, but not systolic BP, was associated with an increased risk (7\%) of cognitive impairment. ${ }^{72}$ Findings of an inverse association between diastolic or systolic BP and cognitive performance (assessed by a wide range of memory, semantic, and fluency tests) that was independent of age, education, employment grade, smoking status, alcohol consumption, use of antihypertensive medication, diagnosis of diabetes, and cardiovascular disease support the existence of a negative relationship between high BP and cognition. ${ }^{73}$ 
In a study of individuals aged 60-64 years, a large proportion (71\%) of those diagnosed as having MCI reverted to a non-MCI status 4 years later, whereas only $11 \%$ of individuals with any MCD reverted to a non-MCD status. ${ }^{13}$ Participants with a history of smoking or harmful levels of alcohol consumption, diagnosed but not medically treated hypertension, anxiety, or depression, were at increased risk of transitioning to MCI or any MCD. ${ }^{13}$ These findings support the notion that modifiable risk factors may contribute to late-life cognitive decline. Of note, decreased CBF in middle-aged individuals has been linked with worse cognition later in life among patients with hypertension, which indicates that hypoperfusion in middle age might mediate late-life cognitive decline in these individuals. ${ }^{74}$

\section{Hypertension and cognition in the elderly- $\mathrm{HYVET}^{75}$ and HYVET-COG ${ }^{76-78}$} enrolled people older than 80 years with uncontrolled hypertension (systolic BP 160-199 $\mathrm{mmHg}$ and diastolic $\mathrm{BP}<110 \mathrm{mmHg}$; Table 3 ). The median minimental state examination (MMSE) score was 26 (maximum 30); the MMSE score was higher at younger age, with male sex, higher educational level, higher creatinine and total-cholesterol levels, and lower HDL-cholesterol levels. Being either underweight or obese was shown to contribute to decline in MMSE scores and was also associated with increased incidence of dementia. ${ }^{77}$ Of note, lower MMSE scores have been associated with higher systolic and lower diastolic BP during sitting and standing in another study. ${ }^{79}$

In the HYVET study, ${ }^{75}$ antihypertensive treatment in elderly patients did not statistically reduce the incidence of dementia. However, this negative finding might have been due to a short follow-up, owing to the early termination of the trial after reductions in mortality and incidence of stroke were demonstrated in association with antihypertensive therapy.

In COGNIPRES, a cross-sectional study of 1,579 patients, ${ }^{80}$ the prevalence of cognitive impairment defined by low MMSE scores was $12.3 \%$. Low MMSE scores were associated with age $>80$ years, uncontrolled BP, and poor compliance to antihypertensive treatment, in addition to history of anxiety, stroke, or transient ischemic attack, and other comorbidities. Overall, BP was controlled only in $28.3 \%$ of participants, and $33.6 \%$ showed poor adherence to antihypertensive treatment. In a prospective community-based cohort of individuals aged $>65$ years residing in Northern Manhattan, USA, hypertension was associated with an increased risk of all-cause MCI and nonamnestic MCI, but not with amnestic MCI. ${ }^{81}$ Hypertension was related to worse executive ability scores, but not to worse memory or language scores, which confirms the specific link between high BP and executive function and attention.

\section{Hypotension and risk of cognitive decline}

Orthostatic hypotension affects about $7 \%$ of the normotensive elderly population and $>30 \%$ of those aged $>75$ years who have other conditions such as diabetes, cardiac diseases, or Parkinson disease. ${ }^{82}$ Orthostatic hypotension increases the risk of stroke, falls, and cognitive decline, ${ }^{82}$ regardless of whether the BP drop is systolic or diastolic and regardless of baseline BP (Table 4). ${ }^{83,84}$ in the ARIC study ${ }^{84}$ the effect of orthostatic hypotension on several cognitive domains was assessed in a cohort of 12,702 participants over 12 years of follow-up. Participants with orthostatic hypotension were more likely to be in the lowest quartile of the Digit Symbol Substitution Test and the Word Fluency Test scores. However, this association was not independent of other cardiovascular and socioeconomic factors.

With orthostatic hypotension, the maintenance of adequate cerebral perfusion at low BP levels depends on autoregulation. Hypoperfusion can develop with impaired autoregulation, or when BP is low, or when BP falls below the autoregulation range, and can lead to cognitive decline. Among patients with $\mathrm{BP}$ in the lower-normal range or hypotension (systolic BP $<120 \mathrm{mmHg}$, diastolic $\mathrm{BP}<70 \mathrm{mmHg}$ ), orthostatic hypotension increases the 
odds of cognitive impairment (measured as $>1$ MMSE score decline; $\mathrm{OR}=4.1,95 \% \mathrm{CI}$ 1.11-15.1). ${ }^{81}$ This effect might be explained by the fact that, in patients with hypotension, perfusion could decline as BP falls below the autoregulated range. By contrast, among patients with hypertension (systolic $\mathrm{BP}>140 \mathrm{mmHg}$, diastolic $\mathrm{BP}>90 \mathrm{mmHg}$ ), the presence of orthostatic hypotension reduces the odds of cognitive impairment $(\mathrm{OR}=0.48,95 \% \mathrm{CI}$ $0.26-0.90) .{ }^{85}$ In patients with hypertension, perfusion can remain within the autoregulated range, or even increase, owing to compensatory vasodilation in response to orthostatic hypotension. Of note, patients with orthostatic hypotension typically have hypertension when in the supine position.

In the Malmö Preventive Project (MPP), ${ }^{86}$ the relationship between orthostatic hypotension and long-term morbidity was assessed in 722 men aged $52.6 \pm 3.6$ years over a follow-up period of $19 \pm 5.3$ years. 5 years after enrollment, $9.9 \%$ of participants had orthostatic hypotension; in $64.5 \%$ of the cases of orthostatic hypotension, a decline in systolic BP, but not in diastolic BP, was observed. Orthostatic hypotension was independently associated with age, low BMI, hypertension, increased heart rate, antihypertensive treatment, diabetes, and current smoking. Men with orthostatic hypotension had an increased risk of coronary events, stroke, and all-cause mortality, as shown in a multivariate adjusted Cox proportional hazard model. Furthermore, participants with orthostatic hypotension, both at baseline and during follow-up, were at the highest risk of any adverse event among the study population $\left(\mathrm{OR}=1.76,95 \%\right.$ CI 1.28-2.43). ${ }^{86}$ The Helsinki Aging Study, ${ }^{87}$ which involved 650 people aged 75-85 years, also found that participants with low general BP had low MMSE scores $(<24)$, whereas hypertension was found to be unrelated to cognitive impairment. In this study, baseline assessments showed that participants with dementia had lower BP than those without dementia and also had signs of left ventricular dysfunction.

BP changes late in life could be the consequence of brain degeneration, or might also be its cause. Declining BP and orthostatic hypotension late in life are markers of general frailty, as they indicate underlying autonomic failure associated with diabetes, Alzheimer disease, Parkinson disease with dementia, Lewy body dementia, and other disorders. The loss of central autonomic regulation and perfusion regulation in late age, which alter the BPperfusion relationship in the setting of hypotension, might have a broad impact on cognitive networks and, ultimately, on morbidity and mortality. The link between these factors, however, remains unclear.

\section{The influence of BP on dementia}

Studies evaluating the relationship between BP, vascular dementia, and Alzheimer dementia have yielded inconsistent results (Table 5). Whether low BP leads to Alzheimer disease or whether Alzheimer disease triggers hypotension is still debated. Cross-sectional and longitudinal data of a bi-racial population aged 60-96 years supported a nonlinear, U-shape relationship between low scores on neuropsychological tests and BP values $<140 \mathrm{mmHg}$ and $>180 \mathrm{mmHg} .{ }^{43,88}$ The prevalence of Alzheimer disease was higher among people with systolic $\mathrm{BP}<130 \mathrm{mmHg}$ and diastolic $\mathrm{BP}<70 \mathrm{mmHg}$ than in the reference group (systolic BP $130-139 \mathrm{mmHg}){ }^{43,88}$

The Honolulu Aging study showed that high systolic BP (the group with 120-140 $\mathrm{mmHg}$ and the group with $>140 \mathrm{mmHg}$ ) in midlife increases the risk of late-life dementia. ${ }^{89}$ Men who developed dementia had an additional age-adjusted increase in systolic BP of 0.26 $\mathrm{mmHg}(95 \% \mathrm{CI} 0.01-0.51 \mathrm{mmHg}$ ) from midlife to late life and a greater decrease in systolic $\mathrm{BP}$ in late life. Up to $58 \%$ of those with dementia experienced a systolic BP decrease of $\geq 10$ $\mathrm{mmHg}$ in late life. The risk ratio [RR] for dementia was lower in patients treated for hypertension than in untreated patients $(\mathrm{RR}=0.76,95 \% \mathrm{CI} 0.65-0.93$ and $\mathrm{RR}=1.05,95 \%$ CI $0.86-1.27$, respectively). ${ }^{66}$ 
In the OPTIMA study, ${ }^{90}$ cognitive function was prospectively evaluated using the Cambridge Cognitive Examination (CAMCOG) tool in 235 cognitively healthy participants, 42 with MCI, 141 with Alzheimer disease, and 59 with other dementia syndrome. In patients with Alzheimer disease, the rate of decline of CAMCOG scores showed a nonlinear, inverted U-shaped dependence on diastolic BP. Both low and high diastolic BP levels $(<60$ $\mathrm{mmHg}$ and $>110 \mathrm{mmHg}$ ) were related to faster cognitive decline over 5 years of follow-up $(z=-2.51, P=0.012)$. CAMCOG scores also showed an inverted $\mathrm{U}$-shaped relationship between pulse pressure and faster progression of Alzheimer disease $(z=-2.29, P=0.022)$. In another study, ${ }^{90}$ low diastolic $\mathrm{BP}(<70 \mathrm{mmHg})$ was associated with a multiadjusted hazard ratio (HR) of 2.13 (95\% CI 1.05-4.32) for incidence of dementia and 2.16 (95\% CI 0.98-4.73) for incidence of Alzheimer disease in people aged $>80$ years over 9-16 years of follow-up, when compared with normal diastolic BP (70-89 $\mathrm{mmHg}$ ). By contrast, higher diastolic BP $(\geq 90 \mathrm{mmHg})$ was only marginally related to a decreased risk of dementia ( $\mathrm{Hr}$ $0.58,95 \%$ CI 0.33-1.02) and of Alzheimer disease (Hr 0.57, 95\% CI 0.30-1.09). Systolic pressure was not significantly related to dementia risk..$^{90}$ Some studies suggest that BP decline could precede the onset of dementia by at least 3 years, ${ }^{4}$ supporting a link between abnormalities in autonomic regulation of BP and dementia risk. In addition, other vascular risk factors—especially high BMI—might interact with BP to increase the risk of dementia. ${ }^{91}$

\section{Antihypertensive therapy and cognition}

Clinical trials in which the impact of antihypertensive therapy on cognitive outcomes was assessed have had conflicting results (Table 6). In the earliest trials, such as the SHEP (Systolic Hypertension in the Elderly Program) ${ }^{92}$ and the Medical Research Council study, ${ }^{93}$ no difference in cognitive function was observed between participants who were treated with antihypertensives and those who were untreated. Later, the Syst-Eur (Systolic Hypertension in Europe) trial showed that hypertension treatment with a calcium-channel blocker was associated with a $50 \%$ reduction in the risk of developing dementia. ${ }^{94,95}$

More recently, the PROGRESS (Perindopril Protection Against Recurrent Stroke Study $)^{96-97}$ indicated that treatment of hypertension with angiotensin-converting enzyme (ACE) inhibitors in patients with previous cerebrovascular disease reduced the risk of dementia and reduced progression of microvascular disease. Patients who were randomly assigned to receive the ACE inhibitor had a $34 \%$ relative risk reduction of the composite outcome of dementia with recurrent strokes (95\% CI 3-55\%, $P=0.03$ ). Similarly, the HOPE (Heart Outcomes Prevention Evaluation) trial ${ }^{98,99}$ found that ACE inhibitors were associated with a $41 \%$ reduction in cognitive decline related to stroke. The SCOPE (Study on Cognition and Prognosis in the Elderly) trial, ${ }^{100,101}$ which used the MMSE to assess cognitive outcome, did not, however, demonstrate a difference between the cognitive function of participants randomly assigned to receive an angiotensin-receptor blocker (ARB) and those not given an ARB. In this study, the group receiving candersartan showed less decline in attention than the group not receiving an ARB, but no differences in working memory were observed. ${ }^{102}$ A major concern related to this trial is that many patients assigned to the 'control' group were already receiving antihypertensive therapy, including ARBs.

In the very elderly ( $>75$ years old), the effect of antihypertensive therapy is even more inconclusive. In HYVET-COG, ${ }^{76,77}$ treatment with an ACE inhibitor had no effect on dementia risk or cognitive decline. However, the median follow-up of this study was only 2 years; the trial was terminated prematurely, because treatment resulted in a $41 \%$ decrease in the primary end point of fatal or nonfatal stroke. Of 4,695 randomly assigned patients, 2,418 
participated in the substudy on dementia. No other study has been designed to address this issue in very elderly individuals.

The combined results of these trials are also not conclusive A pooled analysis of the PROGRESS, SCOPE, SHEP, and Syst-Eur trials, whose participants in the treatment group total 11,794 and those in the control group total 11,711, revealed a nonsignificant association between antihypertensive treatment and the risk of developing dementia (OR $0.89,95 \%$ CI $0.75-1.04) .{ }^{103}$ The heterogeneity measure in this analysis was high, however, and the results were not robust. A meta-analysis of published trials, including HYVET, ${ }^{75}$ demonstrated that, when combined, these studies point to a protective effect of antihypertensive therapy on cognition. ${ }^{75,77}$ However, more recently published trials do not corroborate these findings. For example, in the ProFESS trial, ${ }^{104}$ which used a $2 \times 2$ factorial design, ARB therapy did not provide cognitive protection after stroke. In addition, results from the ONTARGET trial ${ }^{105}$ suggest that systolic BP lowering below the 130-150 $\mathrm{mmHg}$ range using ramipril and telmisartan does not improve outcomes.

The inconsistencies in the results of these trials, individually or when combined in metaanalyses, are likely to be related to differences in the age and, more importantly, in the baseline cognitive function of the populations studied. The cognitive domain being measured is also likely to be an important cause of the observed heterogeneity. Furthermore, many of the trials have used MMSE, a fairly insensitive and nonspecific measure of cognitive change. ${ }^{106}$ Hypertension, however, is more likely to be related to executive function than to overall cognitive performance. ${ }^{107-109}$ Pharmacogenetic variation in cognitive responses, pharmacokinetic characteristics of antihypertensive agents, and study duration are additional factors that lead to heterogeneity in studies of hypertension therapy and cognitive function. A meta-analysis of randomized controlled trials of antihypertensive therapy in the elderly indicated that BP reduction lowers the risk of stroke (35\%), cardiovascular events (27\%), and heart failure (50\%), but does not affect mortality. ${ }^{110} \mathrm{By}$ contrast, small BP reductions and low intensity of therapy were associated with decreased mortality. ${ }^{110}$

Some studies have compared the outcomes achieved with different classes of antihypertensive therapy. The US Veteran Affairs study ${ }^{111}$ determined prospectively that ARBs are more effective in lowering the risk of Alzheimer disease and any dementia compared with the ACE inhibitor lisinopril or other classes of cardiovascular medications. Other trials that assessed the impact of ARBs on cognitive function demonstrated a superior effect of this class of drugs in comparison with the $\beta$-blocker atenolol, ${ }^{112}$ and with the combination of hydrochlorothiazide and lisinopril. ${ }^{13}$ Antihypertensive drugs such as ACE inhibitors (perindopril, captopril), ARBs (losartan), ${ }^{12,114}$ and calcium-channel blockers (nitrendipine) possibly have class-specific effects, and combination therapy might increase cognitive protection. Pharmacokinetic differences within a drug class might also explain this heterogeneity. For example, in the Cardiovascular Health Study, ${ }^{115}$ ACE inhibitors that cross the blood-brain barrier provide cognitive protection, which is not observed with ACE inhibitors that do not cross the blood-brain barrier. Studies of antihypertensive therapy suggest that antihypertensive treatment might be protective against vascular diseases and some of their consequences in the brain. The BP targets that would be protective against cognitive decline remain to be determined in future trials.

\section{Conclusions}

Substantial evidence exists supporting the link between BP and cognition. This relationship might be mediated by impairment of vascular reserve and microvascular disease. Both hypertension and hypotension contribute to cognitive decline, and a combination of vascular 
risk factors during an individual's lifetime could accelerate functional cognitive loss later in life. Combined antihypertensive therapy could have protective effects on vascular disease and cognition. Effective approaches for prevention of cognitive decline, risk reduction, and extension of survival are needed for treatment of hypertension in old age.

\section{Acknowledgments}

V. Novak was supported by grants 1R01AG028076-A2 and 1P01AG028717-01A2 from the National Institute on Aging, NIH and by grant 1R21DK084463-01A1 from the National Institute of Diabetes and Digestive and Kidney Diseases, NIH. I. Hajjar was supported by grant K23AG030057 from the National Institute on Aging, NIH.

Charles P. Vega, University of California, Irvine, CA, is the author of and is solely responsible for the content of the learning objectives, questions and answers of the MedscapeCME-accredited continuing medical education activity associated with this article.

\section{References}

1. Pereira M, Lunet N, Azevedo A, Barros H. Differences in prevalence, awareness, treatment and control of hypertension between developing and developed countries. J Hypertens. 2009; 27 :963975. [PubMed: 19402221]

2. Kearney PM, et al. Global burden of hypertension: analysis of worldwide data. Lancet. 2005; 365:217-223. [PubMed: 15652604]

3. Rutan GH, et al. Orthostatic hypotension in older adults. The Cardiovascular Health Study. CHS Collaborative Research Group. Hypertension. 1992; 19:508-519. [PubMed: 1592445]

4. Qiu C, Winblad B, Fratiglioni L. Low diastolic pressure and risk of dementia in very old people: a longitudinal study. Dement Geriatr Cogn Disord. 2009; 28:213-219. [PubMed: 19752556]

5. Qiu C, Winblad B, Fratiglioni L. The age-dependent relation of blood pressure to cognitive function and dementia. Lancet Neurol. 2005; 4:487-499. [PubMed: 16033691]

6. Moretti R, et al. Risk factors for vascular dementia: hypotension as a key point. Vasc Health Risk Manag. 2008; 4:395-402. [PubMed: 18561514]

7. Rose KM, et al. Orthostatic hypotension and cognitive function: the Atherosclerosis Risk in Communities Study. Neuroepidemiology. 2010; 34:1-7. [PubMed: 19893322]

8. Girouard H, Iadecola C. Neurovascular coupling in the normal brain and in hypertension, stroke, and Alzheimer disease. J Appl Physiol. 2006; 100:328-335. [PubMed: 16357086]

9. Kadoi Y, et al. Diabetic patients have an impaired cerebral vasodilatory response to hypercapnia under propofol anesthesia. Stroke. 2003; 34:2399-2403. [PubMed: 12958324]

10. Katsura K, Rodriguez de Turco EB, Siesjö BK, Bazan NG. Effects of hyperglycemia and hypercapnia on lipid metabolism during complete brain ischemia. Brain Res. 2004; 1030:133-140. [PubMed: 15567345]

11. Staessen JA, Richart T, Birkenhager WH. Less atherosclerosis and lower blood pressure for a meaningful life perspective with more brain. Hypertension. 2007; 49:389-400. [PubMed: 17283254]

12. Winblad B, et al. Mild cognitive impairment—beyond controversies, towards a consensus: report of the International Working Group on Mild Cognitive Impairment. J Intern Med. 2004; 256:240 246. [PubMed: 15324367]

13. Cherbuin N, et al. Risk factors of transition from normal cognition to mild cognitive disorder: the PATH through Life Study. Dement Geriatr Cogn Disord. 2009; 28:47-55. [PubMed: 19628940]

14. Nagai M, Hoshide S, Kario K. Hypertension and dementia. Am J Hypertens. 2010; 23:116-124. [PubMed: 19927134]

15. Panerai RB. Assessment of cerebral pressure autoregulation in humans-a review of measurement methods. Physiol Meas. 1998; 19:305-338. [PubMed: 9735883]

16. Aaslid R, Lindegaard KF, Sorteberg W, Nornes H. Cerebral autoregulation dynamics in humans. Stroke. 1989; 20:45-52. [PubMed: 2492126] 
17. Lipsitz LA, Mukai S, Hammer J, Gagnon M, Babikian VL. Dynamic regulation of middle cerebral artery blood flow velocity in aging and hypertension. Stroke. 2000; 31:1897-1903. [PubMed: 10926954]

18. Novak V, Novak P, Spies JM, Low PA. Autoregulation of cerebral blood flow in orthostatic hypotension. Stroke. 1998; 29:104-111. [PubMed: 9445337]

19. $\mathrm{Hu} \mathrm{K}$, et al. Altered phase interactions between spontaneous blood pressure and flow fluctuations in type 2 diabetes mellitus: nonlinear assessment of autoregulation. Physica A. 2008; 387:22792292. [PubMed: 18432311]

20. Eames PJ, Blake MJ, Dawson SL, Panerai RB, Potter JF. Dynamic cerebral autoregulation and beat-to-beat blood pressure control are impaired in acute ischaemic stroke. J Neurol Neurosurg Psychiatry. 2002; 72:467-473. [PubMed: 11909905]

21. Novak V, et al. Multimodal pressure-flow method to assess dynamics of cerebral autoregulation in stroke and hypertension. Biomed Eng Online. 2004; 3:39. [PubMed: 15504235]

22. Novak V, et al. Altered cerebral vasoregulation in hypertension and stroke. Neurology. 2003; 60:1657-1663. [PubMed: 12771258]

23. Consensus statement on the definition of orthostatic hypotension, pure autonomic failure, and multiple system atrophy. Neurology. 1996; 46:1470. No authors listed. [PubMed: 8628505]

24. Horowitz DR, Kaufmann H. Autoregulatory cerebral vasodilation occurs during orthostatic hypotension in patients with primary autonomic failure. Clin Auton Res. 2001; 11:363-367. [PubMed: 11794717]

25. Novak V, et al. Cerebral flow velocities during daily activities depend on blood pressure in patients with chronic ischemic infarctions. Stroke. 2010; 41:61-66. [PubMed: 19959536]

26. van Lieshout JJ, Wieling W. Perfusion of the human brain: a matter of interactions. J Physiol. 2003; 551:402. [PubMed: 12867571]

27. Davidson E, Rotenbeg Z, Fuchs J, Weinberger I, Agmon J. Transient ischemic attack-related syncope. Clin Cardiol. 1991; 14:141-144. [PubMed: 2044243]

28. Zhang R, Zuckerman JH, Giller CA, Levine BD. Transfer function analysis of dynamic cerebral autoregulation in humans. Am J Physiol. 1998; 274:H233-H241. [PubMed: 9458872]

29. Tiecks FP, et al. Effects of the Valsalva maneuver on cerebral circulation in healthy adults. A transcranial Doppler Study. Stroke. 1995; 26:1386-1392. [PubMed: 7631342]

30. Lundberg N. Continuous recording and control of verntricular fluid pressure in neurosurgical practice. Acta Psychiatr Scand. 1960; 36:1-193.

31. Maeda, M.; Takahashi, K.; Miyazaki, M.; Ishii, S. The role of the central monoamine system and the cholinoceptive pontine area on the oscillation of ICP "pressure waves". In: Miller, JD.; Teasdale, GM.; Rowan, JO.; Galbraith, SL.; Mendelow, AD., editors. Intracranial Pressure VI. Springer-Verlag; Berlin: 1986. p. 151-155.

32. Steinmeier R, et al. Slow rhythmic oscillations in blood pressure, intracranial pressure, microcirculation, and cerebral oxygenation. Stroke. 1996; 27:2236-2243. [PubMed: 8969787]

33. Panerai RB, Eames PJ, Potter JF. Multiple coherence of cerebral blood flow velocity in humans. Am J Physiol Heart Circ Physiol. 2006; 291:H251-H259. [PubMed: 16489099]

34. Latka M, et al. Phase dynamics in cerebral autoregulation. Am J Physiol Heart Circ Physiol. 2005; 289:H2272-H2279. [PubMed: 16024579]

35. Hu K, Peng CK, Czosnyka M, Zhao P, Novak V. Nonlinear assessment of cerebral autoregulation from spontaneous blood pressure and cerebral blood flow fluctuations. Cardiovasc Eng. 2008; 8:60-71. [PubMed: 18080758]

36. Blaber AP, et al. Transfer function analysis of cerebral autoregulation dynamics in autonomic failure patients. Stroke. 1997; 28:1686-1692. [PubMed: 9303010]

37. Schondorf R, Stein R, Roberts R, Benoit J, Cupples WA. Dynamic cerebral autoregulation is preserved in neurally mediated syncope. J Appl Physiol. 2001; 91:2493-2502. [PubMed: 11717210]

38. Bullock R, et al. Cerebral blood flow and $\mathrm{CO}_{2}$ responsiveness as an indicator of collateral reserve capacity in patients with carotid artery disease. Br J Surg. 1985; 72:348-351. [PubMed: 3922463] 
39. Brown GG, Clark C, Liu TT. Measurement of cerebral perfusion with arterial spin labeling: Part 2. Applications. J Int Neuropsychol Soc. 2007; 13:526-538. [PubMed: 17445302]

40. Chimowitz MI, et al. Transcranial Doppler assessment of cerebral perfusion reserve in patients with carotid occlusive disease and no evidence of cerebral infarction. Neurology. 1993; 43:353357. [PubMed: 8437702]

41. Last D, et al. Global and regional effects of type 2 diabetes mellitus on brain tissue volumes and cerebral vasoreactivity. Diabetes Care. 2007; 30:1193-1199. [PubMed: 17290035]

42. Zhao P, et al. Vasoreactivity and peri-infarct hyperintensities in stroke. Neurology. 2009; 72:643649. [PubMed: 19221298]

43. Waldstein SR, Giggey PP, Thayer JF, Zonderman AB. Nonlinear relations of blood pressure to cognitive function: the Baltimore Longitudinal Study of Aging. Hypertension. 2005; 45:374-379. [PubMed: 15699446]

44. Waldstein SR, et al. Pulse pressure and pulse wave velocity are related to cognitive decline in the Baltimore Longitudinal Study of Aging. Hypertension. 2008; 51:99-104. [PubMed: 18025297]

45. Ikram MK, et al. Retinal vessel diameters and cerebral small vessel disease: the Rotterdam Scan Study. Brain. 2006; 129:182-188. [PubMed: 16317022]

46. Vermeer SE, et al. Silent brain infarcts and the risk of dementia and cognitive decline. N Engl J Med. 2003; 27:1215-1222. [PubMed: 12660385]

47. deGroot JC, et al. Cerebral white matter lesions and subjective cognitive dysfunction: the Rotterdam Scan Study. Neurology. 2001; 56:1539-1541. [PubMed: 11402112]

48. Manschot SM, et al. for the Utrecht Diabetic Encephalopathy Study Group. Brain magnetic resonance imaging correlates of impaired cognition in patients with type 2 diabetes. Diabetes. 2006; 55:1106-1113. [PubMed: 16567535]

49. Meyer JS. Regulation of cerebral hemodynamics in health and disease. Eur Neurol. 1983; 22(Suppl. 1):47-60. [PubMed: 6411476]

50. Dandona P, James IM, Newbury PA, Woollard ML, Beckett AG. Cerebral blood flow in diabetes mellitus: evidence of abnormal cerebrovascular reactivity. Br Med J. 1978; 29:325-326. [PubMed: 687900]

51. Appelman AP, et al. White matter lesions and brain atrophy: more than shared risk factors? A systematic review. Cerebrovasc Dis. 2009; 28:227-242. [PubMed: 19571536]

52. deGroot JC, de Leeuw FE, Breteler MM. Cognitive correlates of cerebral white matter changes. J Neural Transm Suppl. 1998; 53:41-67. [PubMed: 9700645]

53. Novak V, Abduljalil AM, Novak P, Robitaille PM. High resolution ultra high field MRI of stroke. Magn Reson Imaging. 2005; 23:539-548. [PubMed: 15919599]

54. Kario K, et al. Diabetic brain damage in hypertension: role of renin-angiotensin system. Hypertension. 2005; 45:887-983. [PubMed: 15824198]

55. Marstrand JR, et al. Cerebral perfusion and cerebrovascular reactivity are reduced in white matter hyperintensities. Stroke. 2002; 34:972-976. [PubMed: 11935046]

56. DeCarli C, et al. The effect of white matter hyperintensity volume on brain structure, cognitive performance, and cerebral metabolism of glucose in 51 healthy adults. Neurology. 1995; 45:20772084. [PubMed: 7501162]

57. Mehagnoul-Schipper DJ, Colier WN, Jansen RW. Reproducibility of orthostatic changes in cerebral oxygenation in healthy subjects aged 70 years and older. Clin Physiol. 2001; 21:77-84. [PubMed: 11168300]

58. Novak V, et al. Cerebral blood flow velocity and periventricular white matter hyperintensities in type 2 diabetes. Diabetes Care. 2006; 29:1529-1534. [PubMed: 16801574]

59. Enzinger C, Fazekas F, Ropele S, Schmidt R. Progression of cerebral white matter lesions-clinical and radiological considerations. J Neurol Sci. 2007; 257:5-10. [PubMed: 17321549]

60. van Raamt RF, et al. for the SMART Study Group. Arterial blood flow to the brain in patients with vascular disease: the SMART Study. Radiology. 2006; 240:515-521. [PubMed: 16864675]

61. Xu WL, Qiu CX, Wahlin A, Winblad B, Fratiglioni L. Diabetes mellitus and risk of dementia in the Kungsholmen project: a 6-year follow-up study. Neurology. 2004; 63:1181-1186. [PubMed: 15477535] 
62. Vermeer SE, et al. for the Rotterdam Scan Study. Silent brain infarcts and white matter lesions increase stroke risk in the general population: The Rotterdam Scan Study. Stroke. 2003; 34:11261129. [PubMed: 12690219]

63. Jokinen H, et al. for the LADIS Group. MRI-defined subcortical ischemic vascular disease: baseline clinical and neuropsychological findings. The LADIS Study. Cerebrovasc Dis. 2009; 27:336-344. [PubMed: 19218799]

64. Sachdev PS, Chen X, Joscelyne A, Wen W, Brodaty H. Amygdala in stroke/transient ischemic attack patients and its relationship to cognitive impairment and psychopathology: the Sydney Stroke Study. Am J Geriatr Psychiatry. 2007; 15:487-496. [PubMed: 17545449]

65. Guo X, et al. Blood pressure components and changes in relation to white matter lesions: a 32-year prospective population study. Hypertension. 2009; 54:57-62. [PubMed: 19487586]

66. Launer LJ, et al. Lowering midlife levels of systolic blood pressure as a public health strategy to reduce late-life dementia: perspective from the Honolulu Heart Program/Honolulu Asia Aging Study. Hypertension. 2010; 55:1352-1359. [PubMed: 20404223]

67. Wolf PA, et al. Relation of obesity to cognitive function: importance of central obesity and synergistic influence of concomitant hypertension. The Framingham Heart Study. Curr Alzheimer Res. 2007; 4:111-116. [PubMed: 17430232]

68. Selim M, Jones R, Novak P, Zhao P, Novak V. The effects of body mass index on cerebral blood flow velocity. Clin Auton Res. 2008; 18:331-338. [PubMed: 18726054]

69. Knopman DS, et al. for the Atherosclerosis Risk in Communities Study Brain MRI Study. Fourteen-year longitudinal study of vascular risk factors, APOE genotype, and cognition: the ARIC MRI Study. Alzheimers Dement. 2009; 5:207-214. [PubMed: 19362884]

70. Pavlik VN, Hyman DJ, Doody R. Cardiovascular risk factors and cognitive function in adults 30 59 years of age (NHANES III). Neuroepidemiology. 2005; 24:42-50. [PubMed: 15459509]

71. Wadley VG, et al. Cognitive status, stroke symptom reports, and modifiable risk factors among individuals with no diagnosis of stroke or transient ischemic attack in the REasons for Geographic and Racial Differences in Stroke (REGARDS) Study. Stroke. 2007; 38:1143-1147. [PubMed: 17322077]

72. Tsivgoulis G, et al. Association of higher diastolic blood pressure levels with cognitive impairment. Neurology. 2009; 73:589-595. [PubMed: 19704077]

73. Singh-Manoux A, Marmot M. High blood pressure was associated with cognitive function in middle-age in the Whitehall II study. J Clin Epidemiol. 2005; 58:1308-1315. [PubMed: 16291476]

74. Kitagawa K, et al. Relationship between cerebral blood flow and later cognitive decline in hypertensive patients with cerebral small vessel disease. Hypertens Res. 2009; 32:816-820. [PubMed: 19575014]

75. Peters R, et al. Vascular risk factors and cognitive function among 3,763 participants in the Hypertension in the Very Elderly Trial (HYVET): a cross-sectional analysis. Int Psychogeriatr. 2009; 21:359-368. [PubMed: 19250558]

76. Peters R, et al. A substudy protocol of the hypertension in the Very Elderly Trial assessing cognitive decline and dementia incidence (HYVET-COG): an ongoing randomised, double-blind, placebo-controlled trial. Drugs Aging. 2006; 23:83-92. [PubMed: 16492072]

77. Peters R, et al. for the HYVET Investigators. Incident dementia and blood pressure lowering in the Hypertension in the Very Elderly Trial cognitive function assessment (HYVET-COG): a doubleblind, placebo controlled trial. Lancet Neurol. 2008; 7:683-689. [PubMed: 18614402]

78. Peters R, et al. Sociodemographic and lifestyle risk factors for incident dementia and cognitive decline in the HYVET. Age Ageing. 2009; 38:521-527. [PubMed: 19553357]

79. Korf ES, White LR, Scheltens P, Launer LJ. Brain aging in very old men with type 2 diabetes: the Honolulu-Asia Aging Study. Diabetes Care. 2006; 29:2268-2274. [PubMed: 17003305]

80. Vinyoles E, De la Figuera M, Gonzalez-Segura D. Cognitive function and blood pressure control in hypertensive patients over 60 years of age: COGNIPRES study. Curr Med Res Opin. 2008; 24:3331-3339. [PubMed: 18954496]

81. Reitz C, Tang MX, Manly J, Mayeux R, Luchsinger JA. Hypertension and the risk of mild cognitive impairment. Arch Neurol. 2007; 64:1734-1740. [PubMed: 18071036] 
82. Hussain M, Ooi WL, Lipsitz LA. Intra-individual postural blood pressure variability and stroke in elderly nursing home residents. J Clin Epidemiol. 2001; 54:488-494. [PubMed: 11337212]

83. Rose KM, et al. Association between the blood pressure response to a change in posture and the 6year incidence of hypertension: prospective findings from the ARIC study. J Hum Hypertens. 2002; 16:771-777. [PubMed: 12444538]

84. Rose KM, et al. Orthostatic hypotension predicts mortality in middle-aged adults: the Atherosclerosis Risk In Communities (ARIC) Study. Circulation. 2006; 114:630-636. [PubMed: 16894039]

85. Yap PL, Niti M, Yap KB, Ng TP. Orthostatic hypotension, hypotension and cognitive status: early comorbid markers of primary dementia? Dement Geriatr Cogn Disord. 2008; 26:239-246. [PubMed: 18841007]

86. Fedorowski A, et al. Consequences of orthostatic blood pressure variability in middle-aged men (The Malmö Preventive Project). J Hypertens. 2010; 28:551-559. [PubMed: 19952779]

87. Kähönen-Väre $M$, et al. Left ventricular hypertrophy and blood pressure as predictors of cognitive decline in old age. Aging Clin Exp Res. 2004; 16:147-152. [PubMed: 15195990]

88. Waldstein SR, Brown JR, Maier KJ, Katzel LI. Diagnosis of hypertension and high blood pressure levels negatively affect cognitive function in older adults. Ann Behav Med. 2005; 29:174-180. [PubMed: 15946111]

89. Stewart R, et al. Change in blood pressure and incident dementia: a 32-year prospective study. Hypertension. 2009; 54:233-240. [PubMed: 19564551]

90. Razay G, Williams J, King E, Smith AD, Wilcock G. Blood pressure, dementia and Alzheimer's disease: the OPTIMA longitudinal study. Dement Geriatr Cogn Disord. 2009; 28:70-74. [PubMed: 19648748]

91. Gorospe EC, Dave JK. The risk of dementia with increased body mass index. Age Ageing. 2007; 36:23-29. [PubMed: 17124253]

92. Applegate WB, et al. Impact of the treatment of isolated systolic hypertension on behavioral variables. Results from the systolic hypertension in the elderly program. Arch Intern Med. 1994; 154:2154-2160. [PubMed: 7944835]

93. Prince MJ, Bird AS, Blizard RA, Mann AH. Is the cognitive function of older patients affected by antihypertensive treatment? Results from 54 months of the Medical Research Council's trial of hypertension in older adults. BMJ. 1996; 312:801-815. [PubMed: 8608285]

94. Forette F, et al. Prevention of dementia in randomised double-blind placebo-controlled Systolic Hypertension in Europe (Syst-Eur) trial. Lancet. 1998; 352:1347-1351. [PubMed: 9802273]

95. Hanon O, Seux ML, Lenoir H, Rigaud AS, Forette F. Prevention of dementia and cerebroprotection with antihypertensive drugs. Curr Hypertens Rep. 2004; 6:201-207. [PubMed: 15128472]

96. Tzourio C, et al. for the PROGRESS Collaborative Group. Effects of blood pressure lowering with perindopril and indapamide therapy on dementia and cognitive decline in patients with cerebrovascular disease. Arch Intern Med. 2003; 163:1069-1075. [PubMed: 12742805]

97. Arima H, et al. for the PROGRESS Collaborative Group. Perindopril-based blood pressure lowering reduces major vascular events in Asian and western participants with cerebrovascular disease: the PROGRESS trial. J Hypertens. 2010; 28:395-400. [PubMed: 19864958]

98. Bosch J, et al. for the HOPE Investigators. Use of ramipril in preventing stroke: double blind randomised trial. BMJ. 2002; 324:699-702. [PubMed: 11909785]

99. Bosch J, et al. for the HOPE/HOPE-TOO Study Investigators. Long-term effects of ramipril on cardiovascular events and on diabetes: results of the HOPE study extension. Circulation. 2005; 112:1339-1346. [PubMed: 16129815]

100. Lithell H, et al. for the SCOPE Study Group. The Study on Cognition and Prognosis in the Elderly (SCOPE): principal results of a randomized double-blind intervention trial. J Hypertens. 2003; 21:875-886. [PubMed: 12714861]

101. Trenkwalder P. The Study on COgnition and Prognosis in the Elderly (SCOPE)—recent analyses. J Hypertens Suppl. 2006; 24:S107-S114. [PubMed: 16601563] 
102. Saxby BK, Harrington F, Wesnes KA, McKeith IG, Ford GA. Candesartan and cognitive decline in older patients with hypertension: a substudy of the SCOPE trial. Neurology. 2008; 70:18581866. [PubMed: 18458219]

103. Feigin V, Ratnasabapathy Y, Anderson C. Does blood pressure lowering treatment prevents dementia or cognitive decline in patients with cardiovascular and cerebrovascular disease? J Neurol Sci. 2005; 229-230:151-155. [PubMed: 15760634]

104. Diener HC, et al. for the PRoFESS Study Group. Effects of aspirin plus extended-release dipyridamole versus clopidogrel and telmisartan on disability and cognitive function after recurrent stroke in patients with ischaemic stroke in the Prevention Regimen for Effectively Avoiding Second Strokes (PRoFESS) trial: a double-blind, active and placebo-controlled study. Lancet Neurol. 2008; 7:875-884. [PubMed: 18757238]

105. Sleight $P$, et al. for the ONTARGET Investigators. Prognostic value of blood pressure in patients with high vascular risk in the Ongoing Telmisartan Alone and in combination with Ramipril Global Endpoint Trial study. J Hypertens. 2009; 27:1360-1369. [PubMed: 19506526]

106. Pendlebury ST, Cuthbertson FC, Welch SJ, Mehta Z, Rothwell PM. Underestimation of cognitive impairment by mini-mental state examination versus the Montreal cognitive assessment in patients with transient ischemic attack and stroke: a population-based study. Stroke. 2010; 41:1290-1293. [PubMed: 20378863]

107. Oveisgharan S, Hachinski V. Hypertension, executive dysfunction, and progression to dementia: the Canadian study of health and aging. Arch Neurol. 2010; 67:187-192. [PubMed: 20142526]

108. Hajjar I, et al. Association of blood pressure elevation and nocturnal dipping with brain atrophy, perfusion and functional measures in stroke and nonstroke individuals. Am J Hypertens. 2010; 23:17-23. [PubMed: 19798036]

109. Hajjar I, et al. A novel aging phenotype of slow gait, impaired executive function, and depressive symptoms: relationship to blood pressure and other cardiovascular risks. J Gerontol A Biol Sci Med Sci. 2009; 64:994-1001. [PubMed: 19535785]

110. Bejan-Angoulvant T, et al. Treatment of hypertension in patients 80 years and older: the lower the better? A meta-analysis of randomized controlled trials. J Hypertens. 2010; 28:1366-1372. [PubMed: 20574244]

111. Li NC, et al. Use of angiotensin receptor blockers and risk of dementia in a predominantly male population: prospective cohort analysis. BMJ. 2010; 340:b5465. [PubMed: 20068258]

112. Fogari R, et al. Influence of losartan and atenolol on memory function in very elderly hypertensive patients. J Hum Hypertens. 2003; 17:781-785. [PubMed: 14578918]

113. Fogari R, et al. Effect of telmisartan/hydrochlorothiazide vs lisinopril/hydrochlorothiazide combination on ambulatory blood pressure and cognitive function in elderly hypertensive patients. J Hum Hypertens. 2006; 20:177-185. [PubMed: 16306998]

114. Tedesco MA, et al. Comparison of losartan and hydrochlorothiazide on cognitive function and quality of life in hypertensive patients. Am J Hypertens. 1999; 12:1130-1134. [PubMed: 10604491]

115. Sink KM, et al. Angiotensin-converting enzyme inhibitors and cognitive decline in older adults with hypertension: results from the Cardiovascular Health Study. Arch Intern Med. 2009; 169:1195-1202. [PubMed: 19597068]

116. Forette F, et al. for the Systolic Hypertension in Europe Investigators. The prevention of dementia with antihypertensive treatment: new evidence from the Systolic Hypertension in Europe (SystEur) study. Arch Intern Med. 2002; 162:2046-2052. [PubMed: 12374512]

117. Muldoon MF, Manuck SB, Shapiro AP, Waldstein SR. Neurobehavioral effects of antihypertensive medications. J Hypertens. 1991; 6:549-559. [PubMed: 1679451]

118. Fogari R, et al. Effects of valsartan compared with enalapril on blood pressure and cognitive function in elderly patients with essential hypertension. Eur J Clin Pharmacol. 2004; 59:863-868. [PubMed: 14747881] 


\section{MedscapeCMESM Continuing Medical Education online}

This activity has been planned and implemented in accordance with the Essential Areas and policies of the Accreditation Council for Continuing Medical Education through the joint sponsorship of Medscape, LLC and Nature Publishing Group. Medscape, LLC is accredited by the ACCME to provide continuing medical education for physicians.

Medscape, LLC designates this educational activity for a maximum of 1.0 AMA PRA Category 1 credits $^{\mathrm{TM}}$. Physicians should only claim credit commensurate with the extent of their participation in the activity. All other clinicians completing this activity will be issued a certificate of participation. To participate in this journal CME activity: (1) review the learning objectives and author disclosures; (2) study the education content; (3) take the post-test and/or complete the evaluation at http://www.medscapecme.com/journal/nrcardio; and (4) view/print certificate.

\section{Learning objectives}

Upon completion of this activity, participants should be able to:

1. Identify clinically relevant biomarkers of brain vascular reserve.

2. Distinguish cognitive domains most likely to be affected by hypertension and examine research into the effects of blood pressure on cognition.

3. Evaluate how antihypertensive therapy may affect cognition. 


\section{Key points}

- Hypertension and hypotension affect neurovascular coupling, leading to a decrease in perfusion, oxygenation, and vascular reserve capacity, and are associated with microvascular disease, stroke, cognitive function decline, and dementia

- Risk factors for vascular disease accelerate age-related decline in perfusion and brain tissue volumes and have additive effects in worsening cognitive outcomes late in life

- Hypertension and other vascular risk factors are linked to poorer performance in executive function and attention tests than in memory or language scores

- Results of antihypertensive treatment in trials for prevention of dementia in the elderly remain inconclusive, but some studies indicate that single-drug or combined antihypertensive therapies have protective effects on cognition

- More research is needed to determine which blood pressure values should be targeted to optimize perfusion and to prevent cognitive decline in the elderly 


\section{Review criteria}

This article is based on a comprehensive search in the PubMed database for full-text articles published in English between 2005 and 2010. Search terms included "hypertension and cognition", "cognition", "white matter hyperintensities", "hypotension and cognition", "blood pressure and dementia", and "antihypertensive therapy". The reference lists of the articles identified during this search were checked for additional articles published since January 2005. 


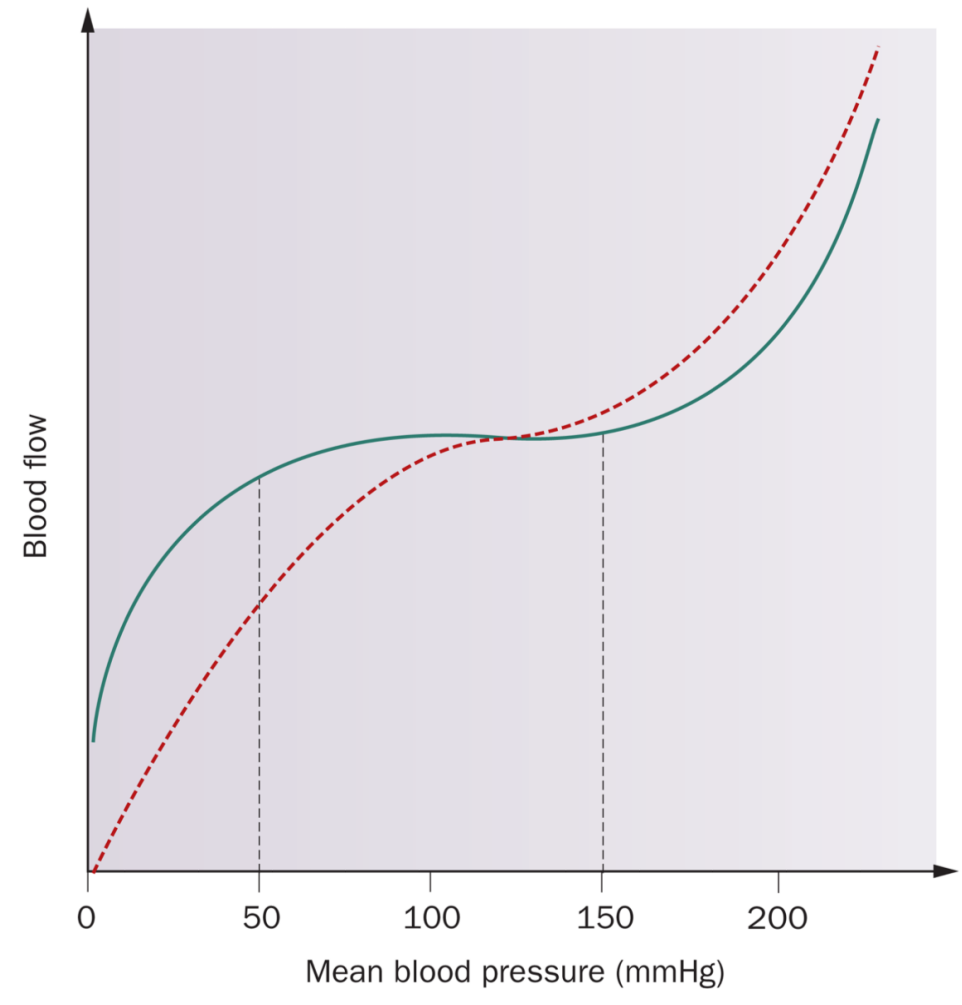

Figure 1.

Normal cerebral autoregulation curve with its lower $(50 \mathrm{mmHg})$ and upper $(150 \mathrm{mmHg})$ limits of mean arterial pressure (green line), and a narrowed range with a steeper curve (red dashed line). 
a

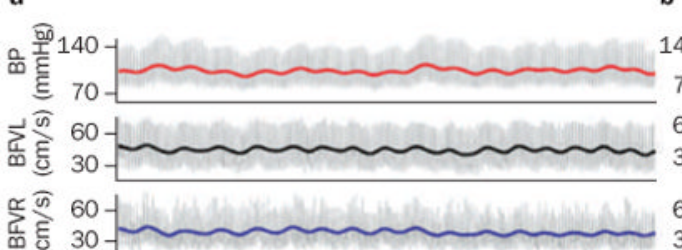

舀䍃 60

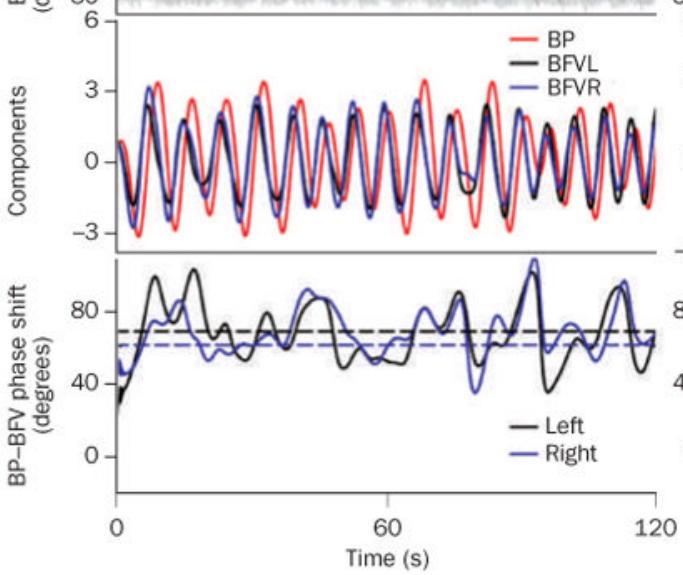

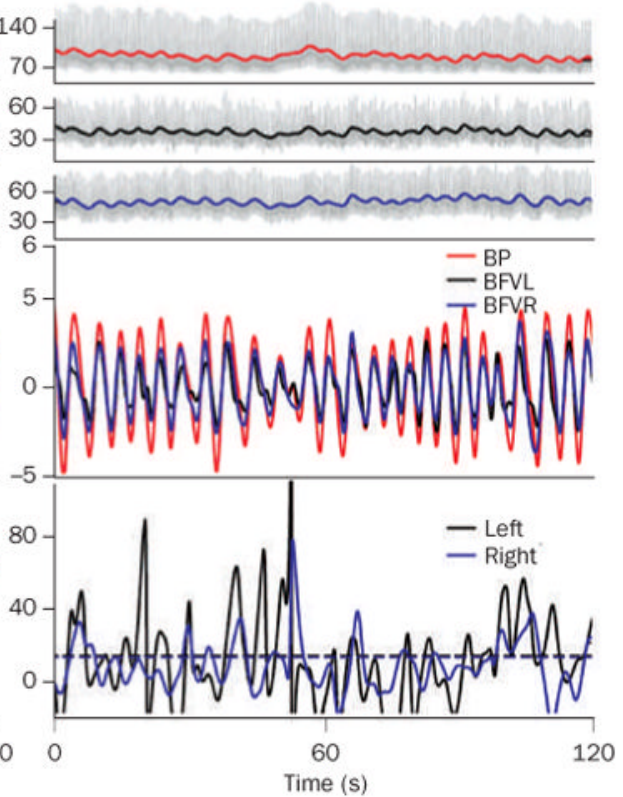

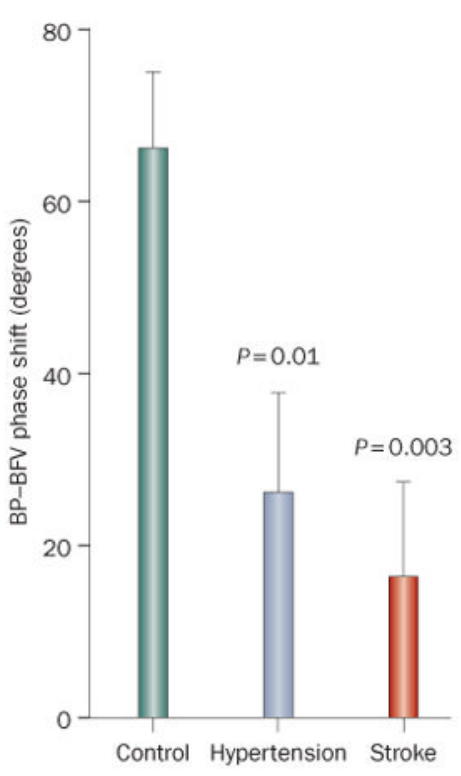

Figure 2.

Relationship between arterial BP and BFV in the middle cerebral artery. a $\mid$ Dominant spontaneous oscillations of BP and BFV in a 72-year-old healthy control woman. b | Dominant spontaneous oscillations of BP and BFV in a 68-year-old man with type 2 diabetes mellitus, in the supine position. BP, BFVL and BFVR were decomposed into different modes, each mode corresponding to fluctuations at a different timescale. BP and BFV fluctuations exhibit continuous and dominant oscillations at frequencies $0.07-0.4 \mathrm{~Hz}$. Instantaneous phases of BP and BFV oscillations (solid lines, bottom graphs) and the mean BP-BFV phase shift (dashed lines) were obtained. $\mathbf{c}$ Phase shift between arterial BP and BFV. Results were obtained from 12 healthy controls, 10 patients with hypertension, and 10 patients with history of stroke, by calculating the instantaneous phase shift during the Valsalva maneuver. Dynamic autoregulation in controls was characterized by specific BPBFV phase shifts. The reduction of the phase shifts observed in participants with hypertension who had never had a stroke and patients with history of stroke indicates impaired autoregulation. Abbreviations: BFV, blood flow velocity; BFVL, left BFV; BFVR, right BFVR; BP, blood pressure. Parts a and b modified with permission from $\mathrm{Hu}$ et al. ${ }^{19}$ Part c reprinted with permission from $\mathrm{Hu}$ et al. ${ }^{35}$ 

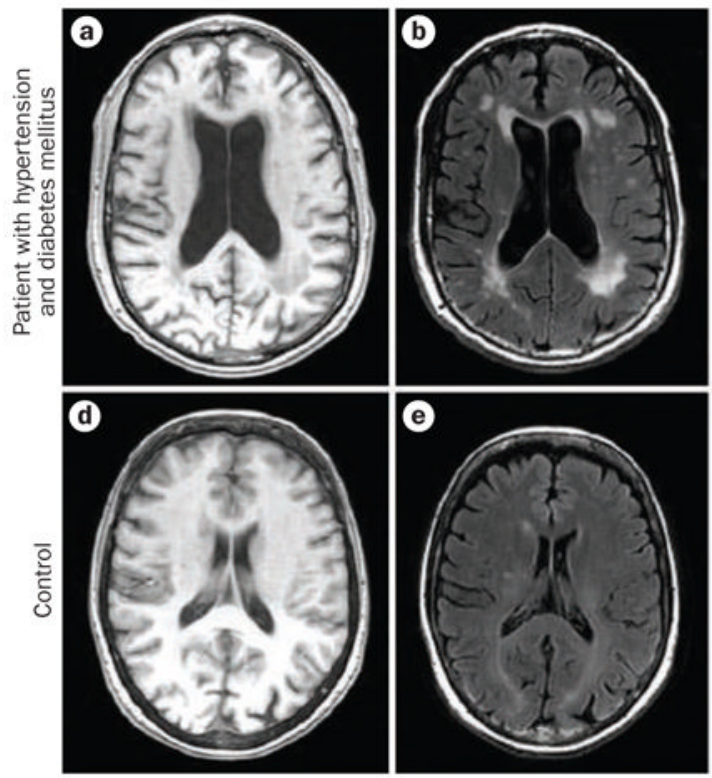

MPRAGE

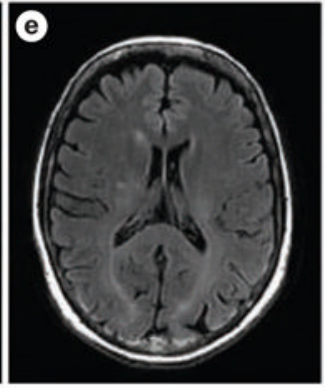

FLAIR
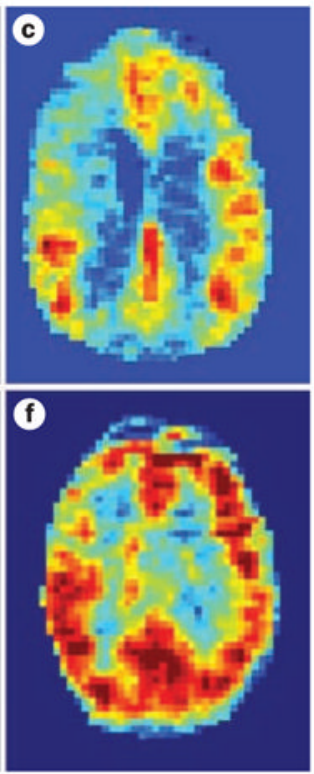

3D CASL

Figure 3.

Anatomical and perfusion images from a patient with hypertension and diabetes mellitus and an age-matched healthy control. a | Brain volume loss. b | Extensive periventricular white matter hyperintensities. $\mathbf{c}$ Reduced perfusion in the frontal and temporal regions. d | Normal brain volume. $\mathbf{e}$ | Absence of white matter hyperintensities. f | Normal perfusion throughout the brain. Abbreviations: 3D CASL, three-dimensional continuous arterial spin labeling; FLAIR, fluid attenuated inversion recovery; MPRAGE, T1-weighted magnetization-prepared rapid acquisition with gradient echography. 

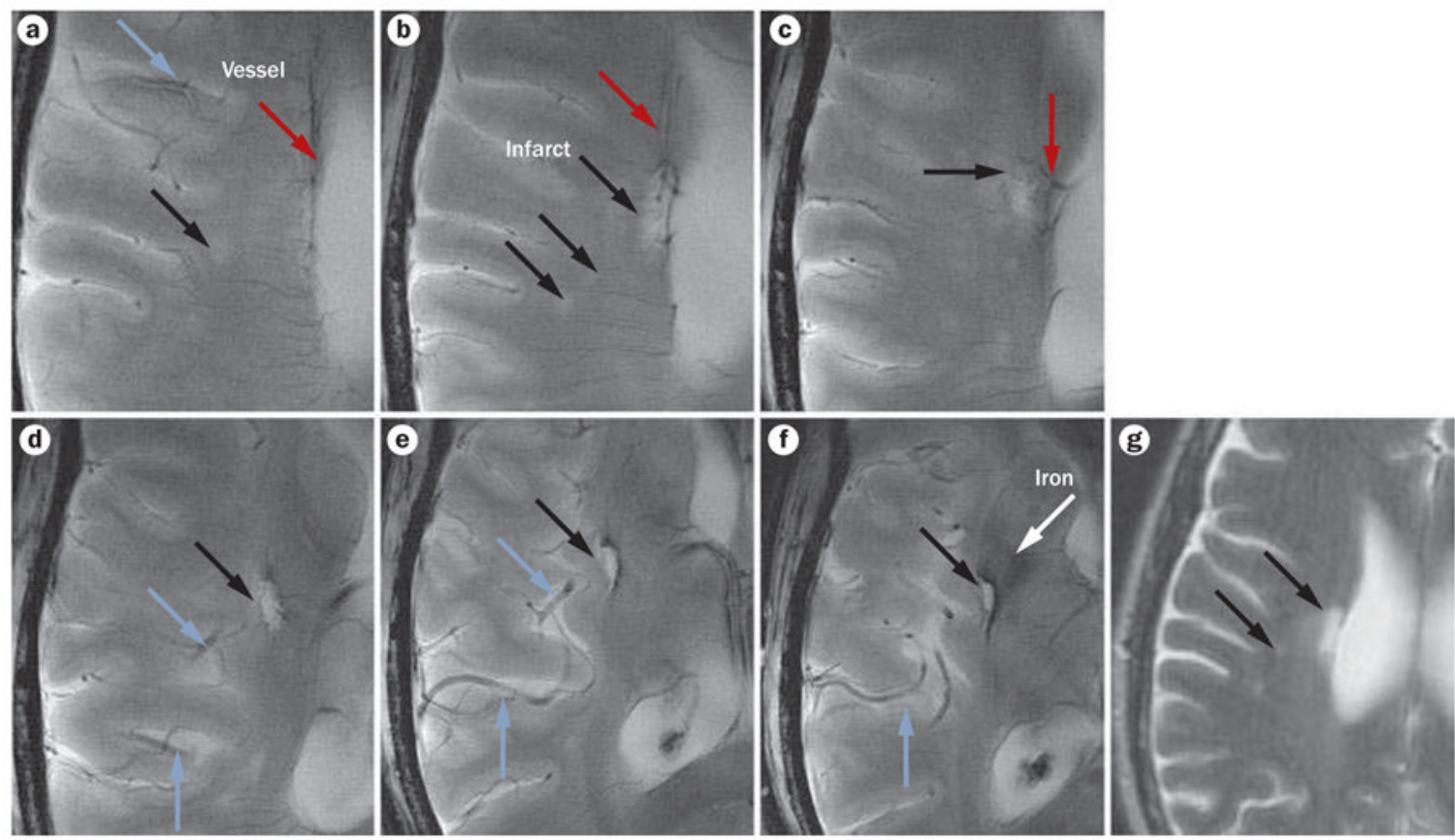

Figure 4.

High resolution 8-T gradient gadolinium-enhanced echography slices (in-plane pixel size $195 \mu \mathrm{m})$. a-f | Vascular supply to the lacunar infarctions and vascular patterns in the infarcted region. Black arrows, infarct sites. Red arrows, small vessel ending within low signal intensity foci in the lacunar infarction. Blue arrows, branches of the cerebral artery supplying infarcted areas. White arrow, larger area of low signal intensity suggestive of iron deposits that extends beyond infarction into the basal ganglia. Iron deposition in brain parenchyma may represent blood-brain-barrier breakdown associated with microvascular disease and microinfarcts. $\mathbf{g} \mid$ Clinical T2-weighted image of the infarcted area (indicated by black arrows), obtained with 1.5-T MRI. Modified with permission from Novak et al. ${ }^{53}$ 
Table 1

Modalities for assessment of vascular reserve

\begin{tabular}{|c|c|c|c|}
\hline Method & Measured variable & Advantages & Limitations \\
\hline Transcranial Doppler utrasonography & $\begin{array}{l}\text { Ultrasound frequency shift } \\
\text { reflecting flow velocity in } \\
\text { large arteries }\end{array}$ & $\begin{array}{l}\text { Temporal resolution (beat- } \\
\text { to-beat } \sim 1 \mathrm{~s} \text { ) } \\
\text { Independent of body } \\
\text { position }\end{array}$ & $\begin{array}{l}\text { Insonation window, angle, and } \\
\text { signal quality } \\
\text { Constant artery diameter } \\
\text { assumption }\end{array}$ \\
\hline $\begin{array}{l}\text { Three-dimensional continuous arterial } \\
\text { spin labeling MRI }\end{array}$ & $\begin{array}{l}\text { Arterial } \mathrm{H}^{+} \text {spin tagging to } \\
\text { measure blood flow }\end{array}$ & $\begin{array}{l}\text { Spatial resolution } \\
\text { Noninvasive measurements } \\
\text { of regional perfusion }\end{array}$ & $\begin{array}{l}\text { Standard template } \\
\text { Signal averaging }(\sim 30 \text { s per } \\
\text { whole brain) } \\
\text { T1 time prolongation by } \\
\text { hematocrit } \\
\text { Magnetic resonance field } \\
\text { inhomogeneities }\end{array}$ \\
\hline Blood-oxygen-level-dependent MRI & $\begin{array}{l}\text { T2*-weighted imaging to } \\
\text { detect differences in } \\
\text { oxygenated and } \\
\text { deoxygenated hemoglobin }\end{array}$ & $\begin{array}{l}\text { Coupling between regional } \\
\text { neuronal activity and blood } \\
\text { flow, with a basis on } \\
\text { changes of blood } \\
\text { oxygenation }\end{array}$ & $\begin{array}{l}\text { Indirect measure of blood flow } \\
\text { and activity } \\
\text { Signal averaging }(\sim 5 \mathrm{~s}) \\
\text { Standard template } \\
\text { Magnetic resonance field } \\
\text { inhomogeneities }\end{array}$ \\
\hline $\begin{array}{l}\text { Single photon emission computed } \\
\text { tomography }\end{array}$ & Technetium-99 & Spatial resolution & $\begin{array}{l}\text { Signal averaging }(\sim 30 \text { s per } \\
\text { projection, typically } 64 \\
\text { projections) } \\
\text { Invasive }\end{array}$ \\
\hline
\end{tabular}




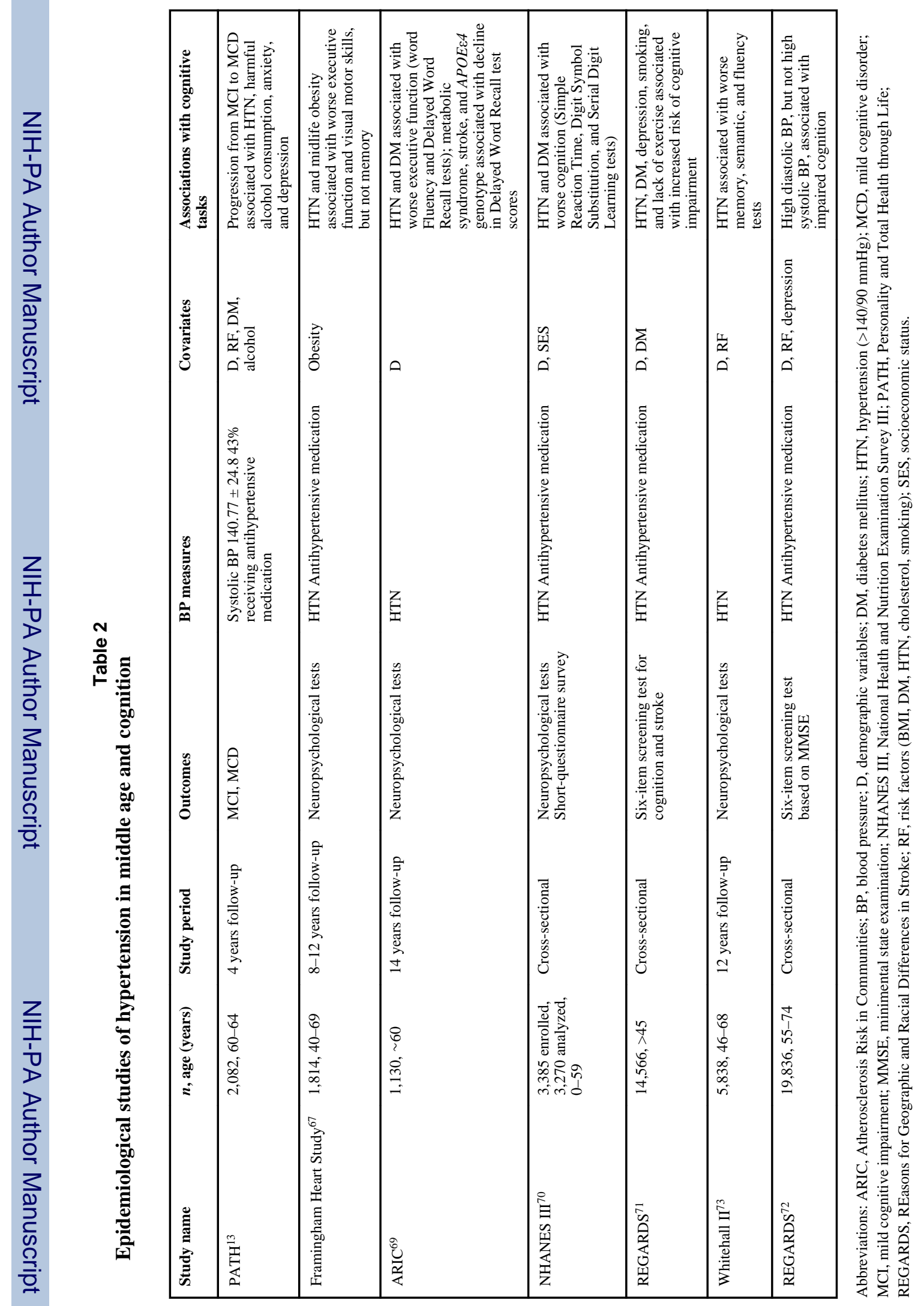

Nat Rev Cardiol. Author manuscript; available in PMC 2012 April 17. 


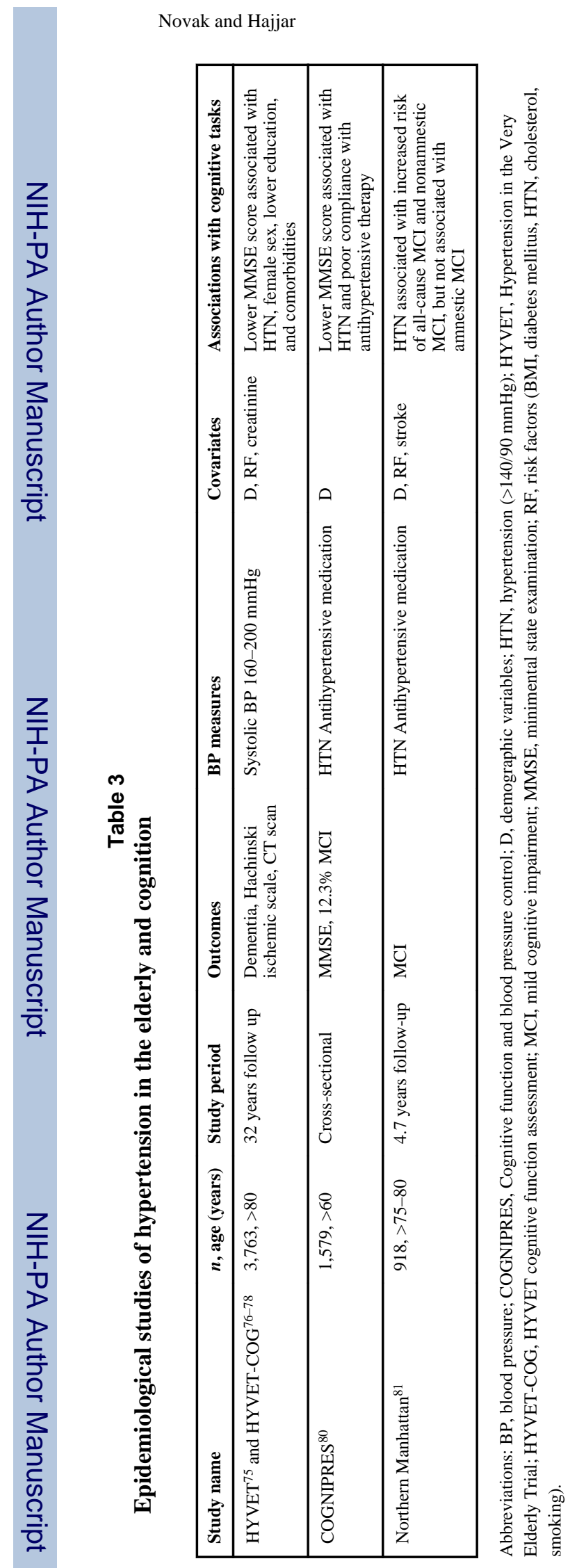

Nat Rev Cardiol. Author manuscript; available in PMC 2012 April 17. 


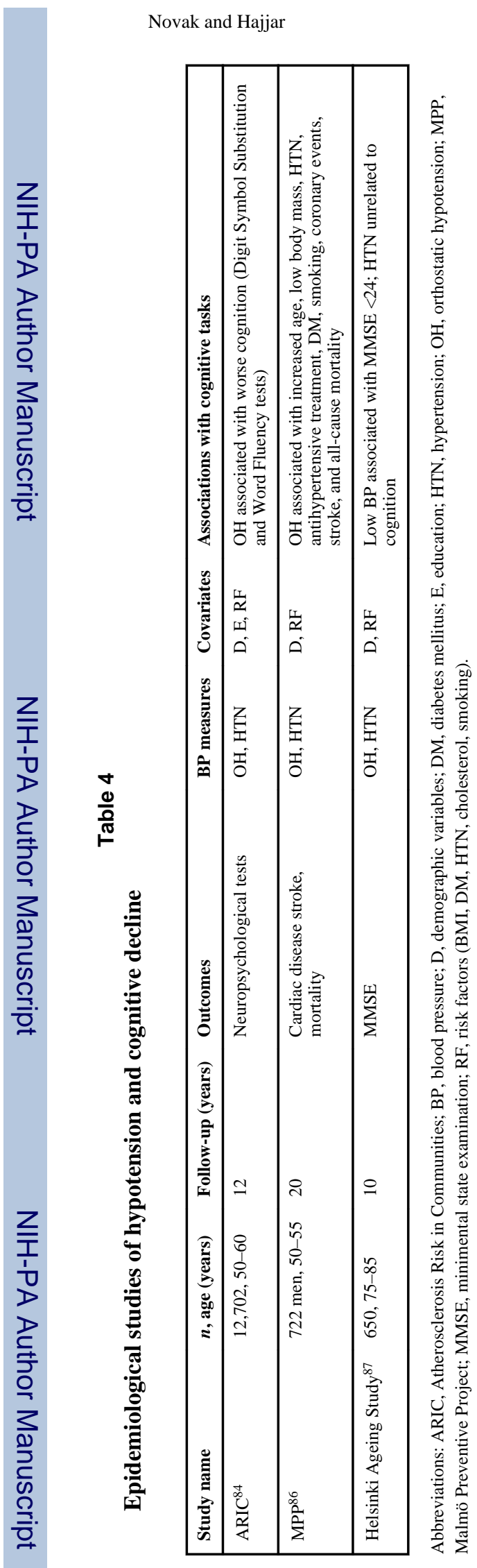

Page 26 


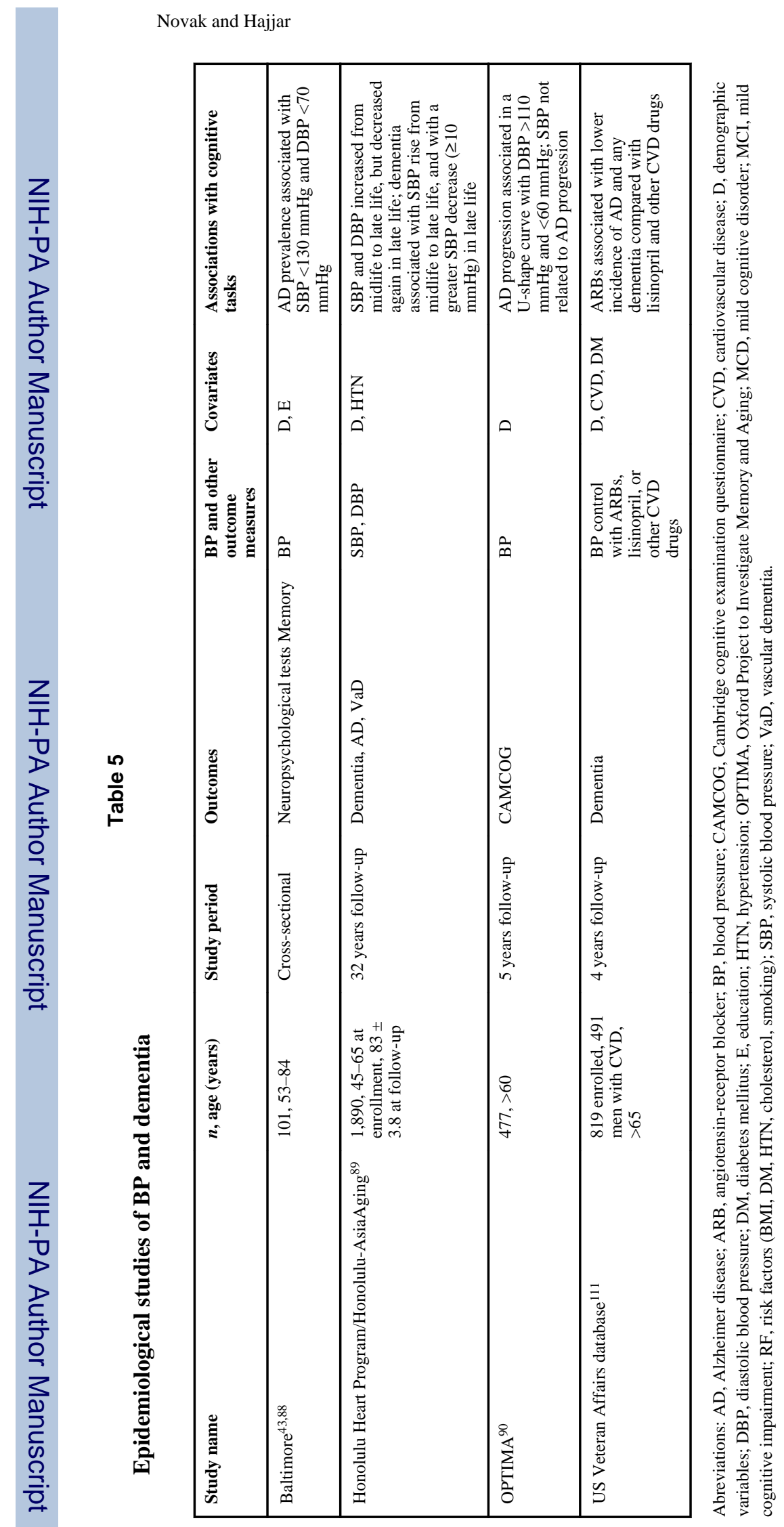

Nat Rev Cardiol. Author manuscript; available in PMC 2012 April 17. 


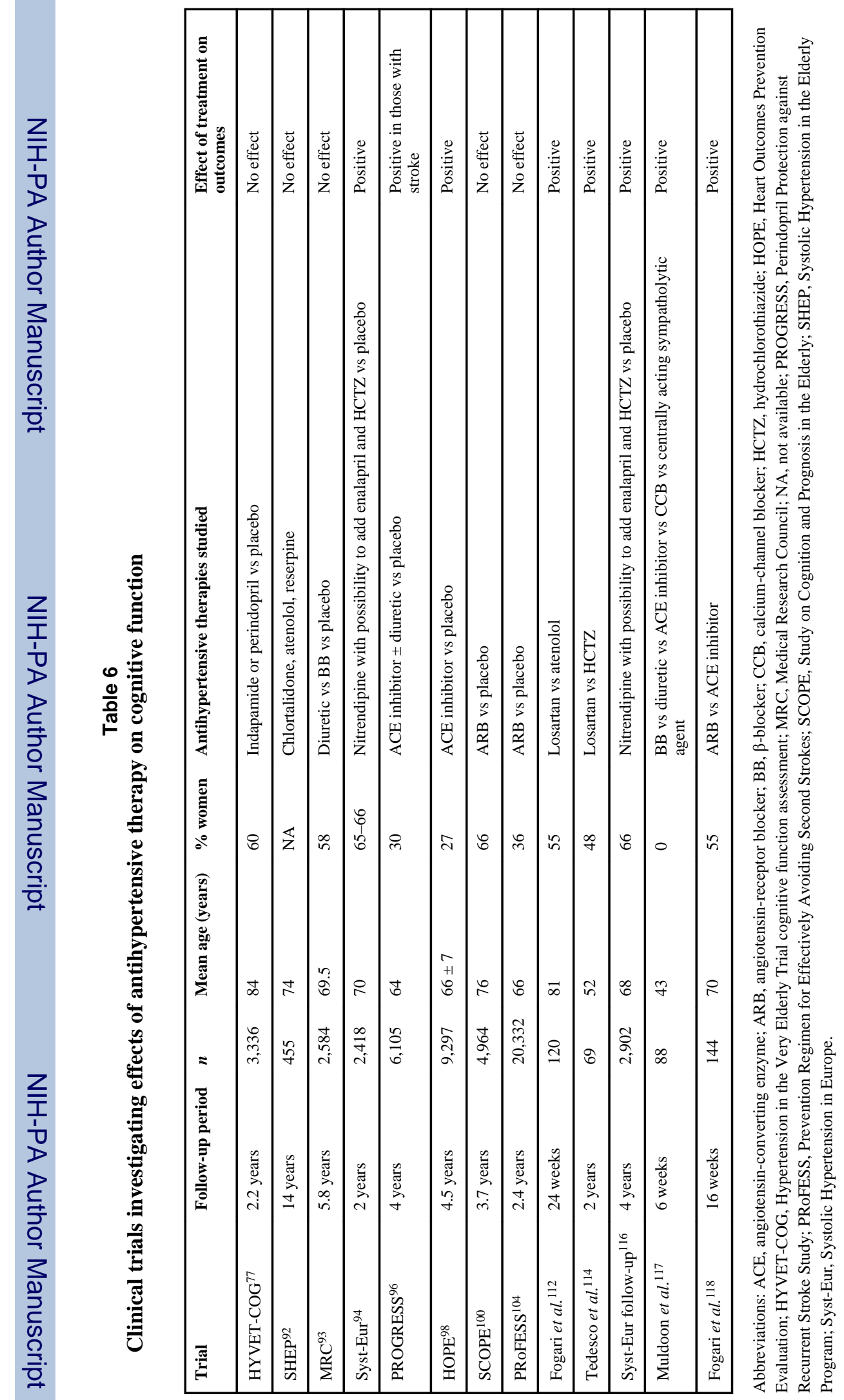

Nat Rev Cardiol. Author manuscript; available in PMC 2012 April 17. 